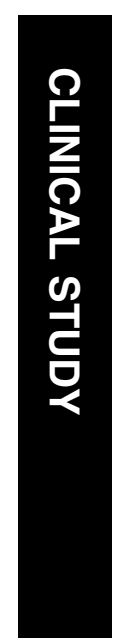

${ }^{1}$ Department of Ophthalmology, Singapore National Eye Centre, Singapore, Singapore

${ }^{2}$ Singapore Eye Research Institute, Singapore, Singapore

${ }^{3}$ Department of Ophthalmology, King's College Hospital, London, UK

${ }^{4}$ Department of Pathology, Institute of Ophthalmology, London, UK

${ }^{5}$ Department of Community, Occupational and Family Medicine, National University of Singapore, Singapore, Singapore

${ }^{6}$ Department of Ophthalmology, National University of Singapore, Singapore, Singapore

Correspondence: MCC Lim, Department of

Ophthalmology,

Singapore National Eye Centre,

11 Third Hospital Avenue, Singapore 168751,

Singapore

Tel: + 6562277255 ;

Fax: + 6562277290 .

E-mail: marcus.lim.c.c@ singhealth.com.sg

Received: 6 February 2008 Accepted in revised form: 21 June 2008

Published online: 1 August 2008

\title{
Direct costs of myopia in Singapore
}

\begin{abstract}
Aims To estimate the direct costs of myopia in Singapore children.

Methods A cross-sectional study of 377

Singaporean school children aged 12-17 years from one school in Singapore Cohort study of the Risk factors for Myopia (SCORM) was conducted. A combination of parent and selfadministered questionnaires asked about the cost of each optometrist visit, spectacles, and contact lenses, transport costs, father's educational level, and total family income. Results A total of 377 subjects participated and cost data were available from 301 subjects. The mean annual direct cost of myopia was S\$221.7 \pm 313.7 (CI, S\$186.5-258.1) or US\$147.8 \pm 209.1 (CI, US\$124.3-172.1) and median annual direct cost of myopia was $S \$ 125.0$ or US $\$ 83.3$. The mean cost per pair of spectacles was $\mathrm{S} \$ 123.2 \pm 61.2$ (CI, $\mathrm{S} \$ 116.6-129.8)$ or US\$82.1 \pm 40.8 (CI, US\$77.8-86.5). Sixty subjects $(15.9 \%)$ wore contact lenses. The mean annual cost of contact lenses was $\mathrm{S} \$ 567.1 \pm 565.7$ (CI, S\$422.2-712.0) or US\$378.1 \pm 377.1 (CI, US\$281.4-474.6). Subjects of families with higher total family income and those with fathers with secondary or higher education had higher annual direct expenditure $(P=0.03$ and $P=0.001$ respectively). Subjects from families with higher household incomes had higher frequency of change of spectacles $(P=0.02)$ and shorter time since the last change of spectacles $(P=0.03)$.

Conclusions The mean annual direct cost of myopia for Singapore school children was S\$221.68 (US\$148) and the median, $S \$ 125.00$ (US\$83.33) per subject. Myopia is associated with significant financial burden in Singapore. Eye (2009) 23, 1086-1089; doi:10.1038/eye.2008.225; published online 1 August 2008
\end{abstract}

Keywords: myopia; cost of illness; Singapore; economics

\section{Introduction}

The fact that myopia affects a significant proportion of school children in East Asia is

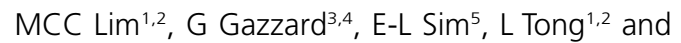
S-M Saw $1,2,5,6$ well established, with a reported prevalence of $73.9 \%$ in Singaporean teenagers. ${ }^{1}$ Its public health costs can be considerable, most obviously from direct costs of refractive correction arising from purchases of spectacles, contact lenses, and their accessories. Globally, myopia cost US $\$ 4.6$ billion in $1990 .{ }^{2}$ The increasingly popular option of laser refractive surgery also has costs, which may be equivalent to wearing soft contact lenses for 10 years. ${ }^{2}$ Other medical costs such as those associated with morbidity arising from myopia, such as retinal detachment, glaucoma and cataract, and associated visual disability and blindness also exist. In this study, we aim to calculate the direct costs of myopia in Singapore teenage school children.

\section{Materials and methods}

The Singapore Cohort study of the Risk factors for Myopia (SCORM) study was a cohort study initiated in 1999 in children in grades 1-3 in two schools and 2001 in the third school. The methodology has been described previously. ${ }^{3-5}$ Children with serious medical or ocular conditions, such as congenital cataract, were excluded from the study. During the 2006 visit, 377 teenagers from one out of the three schools completed a mixed multiple choice and openended questionnaire. There were multiple choice questions on the cost of each visit to the optometrist and cost of current pair of spectacles, frequency of optician visits and spectacles changes, contact lens use, type of contact lens used, transport mode, and duration of one-way journey. Information on father's educational level and total monthly family income were obtained from the parentadministered baseline interview. There were open-ended questions on the frequency of optician visits, spectacles and contact lens changes, spectacles cost, age of current pair of spectacles and contact lenses, number of persons accompanying, and 'other' expenditures. If available, data from openended questions rather than multiple-choice questions were used. 
Table 1 Table summarizing annual direct costs of myopia of participants

\begin{tabular}{|c|c|c|c|c|c|c|}
\hline \multirow[t]{2}{*}{ Category } & \multirow[t]{2}{*}{ Subcategory } & \multirow[t]{2}{*}{$\mathrm{N}$} & \multicolumn{3}{|c|}{ Total costs (Singapore dollars $(S \$)$ : $1 U S \$=1.5 S \$$ ) } & \multirow[t]{2}{*}{ P-value } \\
\hline & & & Mean, $95 \% C I$ & Median & $S D$ & \\
\hline All & & 377 & $221.68(186.651-258.13)$ & 125.00 & 313.73 & \\
\hline \multirow[t]{3}{*}{ Gender } & & 377 & & & & \\
\hline & Male & 163 & 205.36 & 99.00 & 317.06 & 0.38 \\
\hline & Female & 214 & 232.95 & 125.00 & 312.71 & \\
\hline \multirow[t]{4}{*}{ Age as at the first visit (years) } & & 377 & & & & \\
\hline & $\leqslant 7$ & 213 & 218.05 & 99.00 & 344.13 & 0.138 \\
\hline & 8 & 101 & 219.78 & 134.59 & 253.42 & \\
\hline & 9 & 63 & 238.56 & 125.00 & 302.89 & \\
\hline \multirow[t]{3}{*}{ Ethnicity } & & 377 & & & & \\
\hline & Chinese & 281 & 238.20 & 125.00 & 348.97 & 0.119 \\
\hline & Non-Chinese & 96 & 175.89 & 91.33 & 175.83 & \\
\hline \multirow[t]{4}{*}{ Father's educational level } & & 377 & & & & \\
\hline & No formal education & 18 & 171.38 & 84.59 & 181.93 & 0.03 \\
\hline & Primary & 106 & 158.37 & 79.20 & 171.13 & \\
\hline & Secondary and higher & 253 & 250.67 & 127.10 & 358.48 & \\
\hline Total family income & & 367 & & & & \\
\hline$\leqslant \mathrm{S} \$ 2000 /$ month & & 137 & 187.52 & 79.20 & 320.15 & 0.001 \\
\hline S\$2001-S\$5000/month & & 145 & 217.33 & 125.00 & 269.21 & \\
\hline$>\mathrm{S} \$ 5000 /$ month & & 85 & 287.81 & 149.00 & 378.13 & \\
\hline
\end{tabular}

$\mathrm{CI}=$ confidence interval.

We computed the annual direct costs for each participant, which included costs of optician's visits, spectacles, contact lenses, solutions, and total transport costs (including that for persons accompanying) as follows: Cost A was calculated as the annual cost of the optician visit and/or (if not available) spectacles replacement. Contact lens costs (Cost B) were computed with estimates used based on type of contact lens used (Table 1), if actual costs were not stated. The annual transport cost (Cost C) was calculated as twice the cost of the single journey based on the estimates for the participant and number of people accompanying, if any. Transport cost data were not available for 77 subjects. In these cases the mean transport cost of S\$9.59, as calculated for the other 300 subjects, was used. Cost D comprised extraneous items such as orthokeratology lenses. Total annual direct cost was computed as Cost $\mathrm{A}+$ Cost $\mathrm{B}+$ Cost $\mathrm{C}+$ Cost $\mathrm{D}$.

Estimates of monthly costs of contact lenses and solutions were made as follows: daily disposables - S\$140, weekly disposables-S\$35, biweekly disposables - $\$ \$ 30$, monthly disposables - S\$27, and annual lenses - S\$25. Estimates of transport costs used based on mode of transport and duration of journey were made as follows: bus or MRT (mass rapid transit) < $10 \mathrm{~min}-\mathrm{S} \$ 0.75$, 10-30 $\mathrm{min}-\mathrm{S} \$ 1.05$, and $>30 \mathrm{~min}-\mathrm{S} \$ 1.40$; taxi or car $<10 \mathrm{~min}-\mathrm{S} \$ 6.00,10-30 \mathrm{~min}-\mathrm{S} \$ 12.00$, and $>30 \mathrm{~min}-\mathrm{S} \$ 20.00$.

Written informed consent was obtained from the parents and assent was obtained from the child after the nature of the study was explained. Approval was obtained from the Ethics Committee, Singapore Eye Research Institute, and the study's protocol adhered to the tenets of the Declaration of Helsinki. We certify that all applicable institutional and governmental regulations concerning the ethical use of human volunteers were followed during this research. Statistical analysis was carried out using SPSS 11.0 (Chicago, Ill., USA). Wilcoxon rank-sum test, Kruskall-Wallis test, and analysis of variance (ANOVA) were used to compare groups.

\section{Results}

Out of 377 subjects, $301(79.8 \%)$ provided valid cost data from the questionnaires. There were significantly more female subjects in this group $(181,60.1 \%)$ compared to the group, which did not provide enough information $(33,42.9 \%)$ on the questionnaires for cost to be ascertained $(P=0.006)$. However, ethnicity, age of first visit, and household income were not significantly different.

There were $163(43.1 \%)$ male and $214(56.9 \%)$ female subjects; $281(74.3 \%)$ Chinese and $96(25.7 \%)$ nonChinese. Two hundred and thirteen subjects (56.5\%) were aged 12 or less, $101(26.8 \%)$ were aged 13, and $63(16.7 \%)$ were aged 14 years and above. Eighteen (4.8\%) had fathers with no formal education, $106(28.1 \%)$ had fathers with primary education, and $253(67.1 \%)$ had fathers with secondary education or above.

A total of 334 subjects provided spectacles cost data. The mean cost per pair of spectacles was $S \$ 123.2 \pm 61.2$ 
(CI, S\$116.6-129.8) or US\$82.1 \pm 40.8 (CI, US\$77.8-86.5).

Three hundred and twenty-one subjects provided accurate data for the time of last spectacles change. The mean length of time since the last change of spectacles was $1.17 \pm 0.93$ years (CI, 1.06-1.27). Families with higher household incomes had a shorter length of time since the last change of spectacles $(P=0.03)$. There was no significant difference between families with different educational levels of father for length of time since the last change of spectacles. Two hundred and ninety-three subjects provided valid data for cost of the most recent optometrist visit. The mean cost of an optometrist visit was S\$126.1 \pm 59.7 (CI, S\$119.3-133.0). Children from higher income households changed spectacles more frequently $(P=0.02)$, but there was no significant difference between families with different educational levels of father for frequency of spectacles change. A total of 302 patients provided valid data for time since last optometrist visit. The mean time since the last visit was $1.21 \pm 0.85$ years $(\mathrm{CI}, 1.12-1.31)$.

Sixty subjects $(15.9 \%)$ wore contact lenses, including three for orthokeratology. Eight $(13.1 \%)$ wore daily disposables, one (1.6\%) wore weekly disposables, two (3.3\%) wore biweekly disposables, 38 (62.3\%) wore monthly disposables, and 12 (19.7\%) 'others'. The annual median cost for contact lenses was $\$$ \$324.0, while the mean was $\mathrm{S} \$ 567.1 \pm 565.7(\mathrm{CI}, \mathrm{S} \$ 422.2-712.0)$ or US\$378.1 \pm 377.1 (CI, US\$281.5-474.6).

Three hundred $(79.6 \%)$ out of 377 subjects provided accurate transport cost data. The mean transport cost was S\$9.59 or US\$6.39 per subject. The median number of people accompanying the child to the optometrist was 1 .

The mean annual direct cost of myopia was S\$221.70 \pm 313.7 (CI, S\$186.51-258.13) or US\$147.79, and the median, S\$125.00 or US\$83.33 per subject. Gender, age at first visit, and ethnicity had no significant effect, but the cost was significantly different for teenagers whose father had different education or family incomes. The results are summarized in Table 1 .

\section{Discussion}

Our estimated (median) annual direct cost of myopia per child of S\$125 is significant, especially when compared with an estimate of US\$90 per capita direct cost of treating major visual disorders (visual impairment, blindness, refractive error, age-related macular degeneration, cataracts, diabetic retinopathy, and primary open-angle glaucoma) in the United States. ${ }^{6} \mathrm{We}$ have to bear in mind that the direct costs of refractive error used for calculation in those studies do not go beyond basic eyeglasses. The only other cost data for eye diseases in Singapore is a direct cost study on acute angle-closure glaucoma, showing that it would cost
Singaporeans up to US\$300 000 over 5 years. ${ }^{7}$ This works out as nearly 2 cents per capita, which is very small in comparison to our calculated costs of myopia.

From Singapore population data ${ }^{8}$ together with data describing age-specific prevalence rates of myopes from existing studies, ${ }^{1,9-11}$ we estimate that there are approximately 300000 Singaporean teenage myopes in Singapore. Using our median annual direct cost of myopia of $S \$ 125$ the annual direct cost of treating myopia in Singaporean teenagers is therefore $\$ \$ 37.5$ million (US\$25 million).

It has been estimated that US\$8.1 billion was spent on vision products (eyeglass frames, lenses, and contact lenses) in $1990 .{ }^{12}$ A cross-sectional study in the United States showed that 110 million Americans could achieve normal vision with refractive correction and the estimated cost for this was US $\$ 3.8$ billion. ${ }^{13}$ This equates to approximately US\$35 per person or US\$13 per capita annually, based on the cost of a pair of spectacles and refraction examination. In that study, the refractive error corrected included myopia, hyperopia, and presbyopia. Our study, in myopes only, shows that the direct costs for myopic refractive correction in Singapore school children are higher. This is probably because our study was on a prospective cohort of myopes measuring actual expenditures by actual people, and not a theoretical extrapolation. The amount that a private individual is willing to pay is larger than the amount the government is willing to subsidize. The difference could be equated to the extra amount that the private individuals are willing to pay for other factors such as aesthetics, as it is possible to get a cheap pair of spectacles in Singapore for US\$35.

Although market research has been carried out extensively, there has been little research done by academics in this area in the past, most likely because the direct costs of refractive correction are usually borne by the individual, eg, in Singapore, not the state. On the contrary, in some countries, eg, the United Kingdom, some segments of the population are entitled to eye glasses subsidized by the government. As expected, the range of spectacles that can be chosen under this scheme is limited to the cheapest and most basic.

With the increasing prevalence rates of myopia in East Asia, the cost of treating myopia will remain significant. There is evidence that factors such as amount of near work, number of books read, higher non-verbal IQ, and better exam results are associated with myopia. ${ }^{4,14-17}$ Atropine has been shown to retard myopia progression. ${ }^{18}$

In our study, there was evidence to suggest that socioeconomic factors may affect the expenditure associated with myopia. In particular, subjects of families with higher total family income and those with fathers with secondary or higher education had higher annual direct expenditures, while subjects from families with 
higher household incomes had higher frequency of change of spectacles and shorter time since the last change of spectacles. The median expenditure for myopia for those earning $\leqslant$ S\$2000/month was $\$ \$ 79.20$, while for families earning $>S \$ 5000 /$ month, it was $\mathrm{S} \$ 149.00$. In economic terms, this means that there is a positive income elasticity of demand for myopia correction, with spectacles and contact lenses being 'normal goods', where the change in demand divided by the change in income is between 0 and 1 . With increasing prosperity and increasing incomes, the amount spent on myopia correction can be forecasted to increase.

A limitation of our study in evaluating costs in teenagers includes the fact that the data may not be reliable, as it is their parents filling in the cost data retrospectively in the questionnaire. A prospective method of data collection would no doubt be more accurate.

We did not calculate the indirect costs, as with most cost studies of ophthalmologic diseases. These costs include lost workdays, restricted activity days, caregiver costs, and cost of suffering associated with untreated myopia. Transportation costs are classified under direct costs. The number of untreated myopes in a developed society like Singapore would be small compared to that in a developing country, but nonetheless cannot be ignored. It has been shown that a considerable number of adults in Singapore have untreated refractive error, more than when compared to other populations. ${ }^{19}$ The utility values for myopia are not insignificant, as Singaporean teenagers are willing to incur a $7 \%$ decrease in life or a $15 \%$ risk of blindness to avoid myopia. ${ }^{20}$ The cost of productivity losses for visual disorders in the United States is approximately US\$8 billion, half the direct costs. ${ }^{6}$ Hence, the significant indirect costs of myopia exist which further studies are needed to clarify.

In summary, in Singapore, the direct cost to society of myopia in school children is significant, especially with the high prevalence of myopia. More wealthy families spend more on myopia correction. With increasing myopia and prosperity, this cost can only escalate.

\section{Acknowledgements}

This study is supported by the National Medical Research Council NMRC/0975/2005.

\section{References}

1 Quek TP, Chua CG, Chong CS, Chong JH, Hey HW, Lee J et al. Prevalence of refractive errors in teenage high school students in Singapore. Ophthalmic Physiol Opt 2004; 24: 47-55.
2 Javitt JC, Chiang YP. The socioeconomic aspects of laser refractive surgery. Arch Ophthalmol 1994; 112: 1526-1530.

3 Saw SM, Nieto FJ, Katz J, Chew SJ. Estimating the magnitude of close-up work in school-age children: a comparison of questionnaire and diary instruments. Ophthalmic Epidemiol 1999; 6: 291-301.

4 Saw SM, Chua WH, Hong CY, Wu HM, Chia KS, Stone RA et al. Height and its relationship to refraction and biometry parameters in Singapore Chinese children. Invest Ophthalmol Vis Sci 2002; 43: 1408-1413.

5 Saw SM, Tong L, Chua WH, Chia KS, Koh D, Tan DT et al. Incidence and progression of myopia in Singaporean school children. Invest Ophthalmol Vis Sci 2005; 46: 51-57.

6 Rein DB, Zhang P, Wirth KE, Lee PP, Hoerger TJ, McCall N et al. The economic burden of major adult visual disorders in the United States. Arch Ophthalmol 2006; 124: 1754-1760.

7 Wang JC, Chew PT. What is the direct cost of treatment of acute primary angle closure glaucoma? The Singapore model. Clin Experiment Ophthalmol 2004; 32: 578-583.

8 Singapore Department of Statistics. Singapore Resident Population, 1990-2006. 2006.

9 Tan GJ, Ng YP, Lim YC, Ong PY, Snodgrass A, Saw SM. Cross-sectional study of near-work and myopia in kindergarten children in Singapore. Ann Acad Med Singapore 2000; 29: 740-744.

10 Wong TY, Foster PJ, Hee J, Ng TP, Tielsch JM, Chew SJ et al. Prevalence and risk factors for refractive errors in adult Chinese in Singapore. Invest Ophthalmol Vis Sci 2000; 41: 2486-2494.

11 Wu HM, Seet B, Yap EP, Saw SM, Lim TH, Chia KS. Does education explain ethnic differences in myopia prevalence? A population-based study of young adult males in Singapore. Optom Vis Sci 2001; 78: 234-239.

12 Levit KR, Lazenby HC, Cowan CA, Letsch SW. National health expenditures, 1990. Health Care Fin Rev 1991; 13: 29-54.

13 Vitale S, Cotch MF, Sperduto R, Ellwein L. Costs of refractive correction of distance vision impairment in the United States, 1999-2002. Ophthalmology 2006; 113: 2163-2170.

14 Saw SM, Chua WH, Hong CY, Wu HM, Chan WY, Chia KS et al. Nearwork in early-onset myopia. Invest Ophthalmol Vis Sci 2002; 43: 332-339.

15 Saw SM, Carkeet A, Chia KS, Stone RA, Tan DT. Component dependent risk factors for ocular parameters in Singapore Chinese children. Ophthalmology 2002; 109: 2065-2071.

16 Saw SM, Tan SB, Fung D, Chia KS, Koh D, Tan DT et al. IQ and the association with myopia in children. Invest Ophthalmol Vis Sci 2004; 45: 2943-2948.

17 Saw SM, Cheng A, Fong A, Gazzard G, Tan DT, Morgan I. School grades and myopia. Ophthalmic Physiol Opt 2007; 27: 126-129.

18 Chua WH, Balakrishnan V, Chan YH, Tong L, Ling Y, Quah BL et al. Atropine for the treatment of childhood myopia. Ophthalmology 2006; 113: 2285-2291.

19 Saw SM, Foster PJ, Gazzard G, Friedman D, Hee J, Seah S. Undercorrected refractive error in Singaporean Chinese adults: the Tanjong Pagar survey. Ophthalmology 2004; 111: 2168-2174.

20 Saw SM, Gazzard G, Au Eong KG, Koh D. Utility values and myopia in teenage school students. $\mathrm{Br} J$ Ophthalmol 2003; 87: 341-345. 